Int. J. Dev. Biol. 63: 371-382 (2019)

https://doi.org/10.1387/ijdb.190158jm

\title{
Cooperation and conflict in the social amoeba Dictyostelium discoideum
}

\author{
JAMES M. MEDINA, P.M. SHREENIDHI, TYLER J. LARSEN, DAVID C. QUELLER and JOAN E. STRASSMANN* \\ Department of Biology. Washington University, St. Louis MO, USA
}

\begin{abstract}
The social amoeba Dictyostelium discoideum has provided considerable insight into the evolution of cooperation and conflict. Under starvation, $D$. discoideum amoebas cooperate to form a fruiting body comprised of hardy spores atop a stalk. The stalk development is altruistic because stalk cells die to aid spore dispersal. The high relatedness of cells in fruiting bodies in nature implies that this altruism often benefits relatives. However, since the fruiting body forms through aggregation there is potential for non-relatives to join the aggregate and create conflict over spore and stalk fates. Cheating is common in chimeras of social amoebas, where one genotype often takes advantage of the other and makes more spores. This social conflict is a significant force in nature as indicated by rapid rates of adaptive evolution in genes involved in cheating and its resistance. However, cheating can be prevented by high relatedness, allorecognition via tgr genes, pleiotropy and evolved resistance. Future avenues for the study of cooperation and conflict in $D$. discoideum include the sexual cycle as well as the relationship between $D$. discoideum and its bacterial symbionts. $D$. discoideum's tractability in the laboratory as well as its uncommon mode of aggregative multicellularity have established it as a promising model for future studies of cooperation and conflict.
\end{abstract}

KEY WORDS: kin selection, kin recognition, arms races, altruism, relatedness

\section{Introduction}

The study of cooperation and conflict among living organisms has traditionally focused on the behavior of social animals like ants, lions, or primates, but the central ideas apply to all life. Cooperation and conflict are of great evolutionary importance even to organisms with no intelligence and no behavior in the conventional sense. One microbe - the social amoeba Dictyostelium discoideum - has in recent decades taken a special significance for scientists seeking to understand how cooperation and conflict evolve. Its tractability in laboratory studies, its long history as a model for studying development and immunology, and most importantly its unusual life cycle make it particularly useful (Kaushik and Nanjundiah, 2003; Kessin, 2001; Li and Purugganan, 2011; Ostrowski, 2019; Shaulsky and Kessin, 2007; Strassmann and Queller, 2011).

$D$. discoideum and its relatives are cellular slime molds found in soils throughout the world (Swanson et al., 1999). D. discoideum spends most of its life as a single-celled, vegetative amoeba, traveling through the soil and preying upon bacteria. As bacterial prey are depleted and the amoebas begin to starve, $D$. discoideum enters a unique social cycle (Fig. 1). Previously solitary cells rapidly transition to multicellularity, aggregating into a slug-like multicellular body of tens to hundreds of thousands of cells. The slug migrates to a suitable spot and matures into a fruiting body, its constituent cells developing into a sorus of durable spores which can wait dormant for conditions to improve and a tall stalk to hold the sorus aloft and increase the spores' chances of being dispersed by a passing invertebrate (Bonner, 1967; Kessin, 2001; smith et al., 2014). Crucially, the development of the stalk is an act of altruism by stalk cells, which die in the process of helping spore cells survive and disperse.

Therein lies a problem. Natural selection should only select for adaptations that increase the reproductive success of individuals carrying the genes underlying them. Cells that die to produce the fruiting body's stalk cannot pass on their genes to the next generation. Only spores - those cells which did not sacrifice themselves - live to produce progeny. Stalk cells pay a price and seem to receive nothing in return. Why, then, does natural selection not eliminate stalk production altogether? Why do 'cheaters' - strains which abandon or reduce their investment in stalk production to take advantage of the stalks produced by cooperators - not rapidly overtake the population?

*Address correspondence to: Dr. Joan E. Strassmann. Department of Biology. Washington University, One Brookings Drive, Campus Box 1137, St. Louis MO 63130,
USA. Tel: +1 832-978-5961. Fax: +1 (314) 935-4432. E-mail: strassmann@ wustl.edu - (D) https://orcid.org/0000-0003-0638-8440

Submitted: 1 May, 2019; Accepted: 22 June, 2019.

ISSN: Online 1696-3547, Print 0214-6282

(C) 2019 UPV/EHU Press

Printed in Spain 


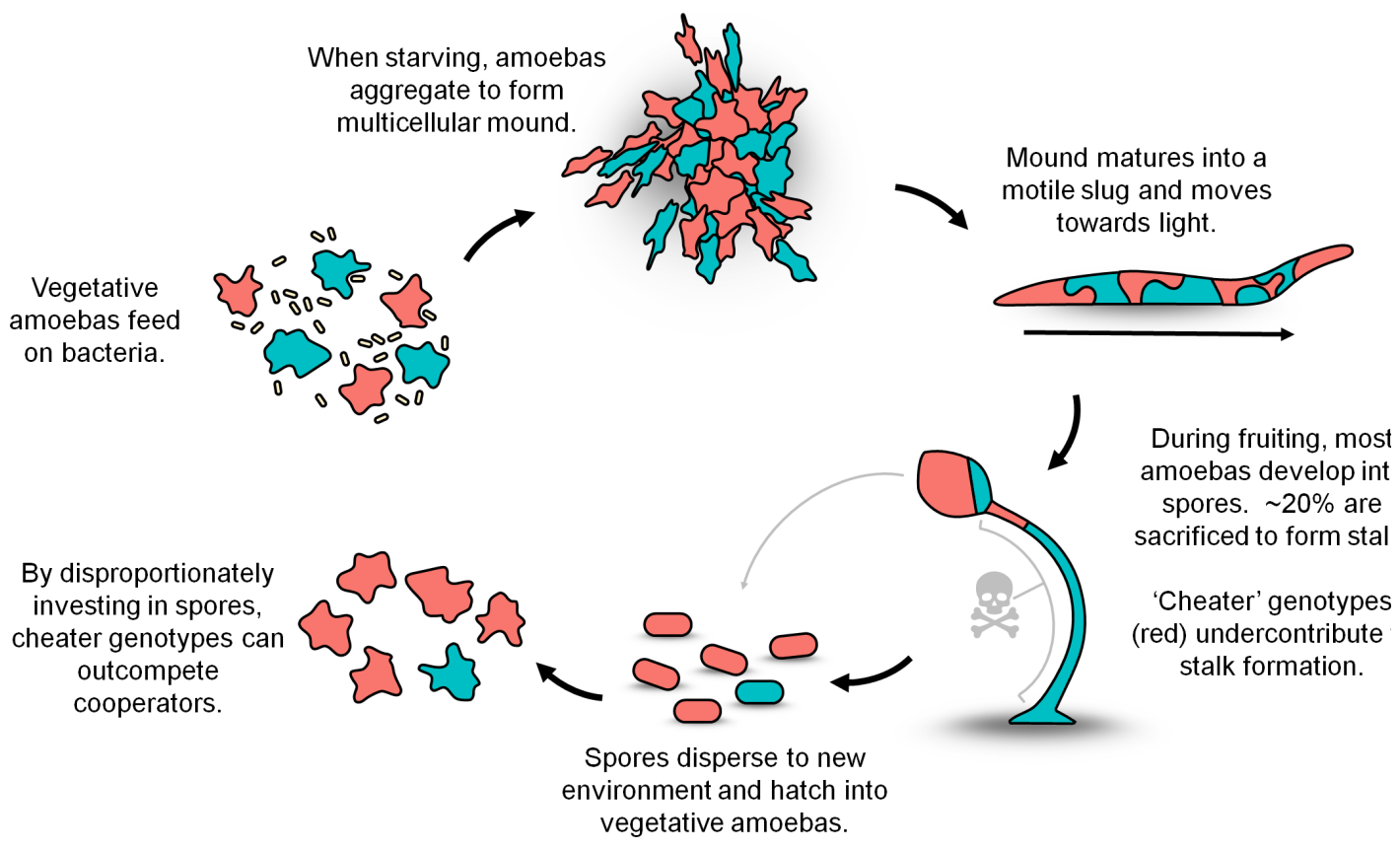

Fig. 1. Social cycle of $\boldsymbol{D}$. discoideum. When starved, single-celled amoebas aggregate into a slug-like multicellular body, then fruit. Fruiting body production requires the sacrifice of a minority of cells to produce a stalk. The potential for aggregation of multiple genotypes into a chimeric fruiting body gives opportunity to selfish 'cheater' genotypes (red), which benefit from but do not contribute to the stalks produced by other genotypes.

The self-sacrifice of Dictyostelium stalk cells is analogous to the sterility of social insect workers, the suicidal stinging defense of honeybees, the risky cooperative hunting of larger prey by pack hunting mammals, and myriad other examples with the same potential evolutionary pitfalls. Why should any organism evolve a capacity to sacrifice its own reproduction for the reproduction of others? This is the problem of altruism, and it is one of the historic puzzles in evolutionary biology. Altruistic traits should be evolutionarily unstable and yet such traits appear throughout nature.

An important answer arrived in the 1960s when William Hamilton quantitatively formalized a general explanation for the evolution of apparently altruistic behaviors called inclusive fitness theory or kin selection theory (Hamilton, 1964a; Hamilton, 1964b). Under inclusive fitness theory, natural selection acts on individuals' inclusive fitness, which consists of both their personal or direct fitness - their lifetime reproductive success - as well as any fitness obtained through their effects on genetic relatives. By helping close relatives reproduce, individuals can indirectly transmit copies of their genes to the next generation. Selection on benefits to kin can thus even select for extreme altruistic traits (like stalk production in $D$. discoideum) where some individuals sacrifice themselves entirely for their kin. Inclusive fitness theory has proven to have a great deal of explanatory power, not only in justifying the existence of altruism, but also for predicting phenomena like worker policing and extreme sex ratios in social insect colonies (Bourke, 2011; Bourke and Franks, 1995; Queller, 2016; Ratnieks et al., 2006; Strassmann et al., 2011).

Inclusive fitness theory does much to explain why $D$. discoideum might retain self-sacrificial traits like stalk formation. In many fruiting bodies, just as in the bodies of more conventional multicellular organisms like animals, most or all of the constituent cells will be clones, and as such any gene present in a would-be stalk cell is very likely to be present in the spore cell the stalk cell's self-sacrifice would benefit. If fruiting bodies were all clonal, the costs of a subset of cells dying to produce a stalk could be compensated for by the dispersal and/or survival benefits afforded to the rest of the cells. Major questions remain, however. Even in a clonal organism, mutation can produce new variation and reduce relatedness (though this appears not to be a major problem in $D$. discoideum (Kuzdzal-Fick et al., 2011)). More importantly - and unlike most other multicellular organisms $-D$. discoideum forms its multicellular body via the aggregation of all nearby cells, whether they are clonemates or not. This opens opportunities for fruiting bodies to have relatedness much lower than one, and thus for the evolution of conflict and the disruption of cooperation.

$D$. discoideum and its relatives have persisted in performing their social life cycles in the face of potential conflict and evolutionary instability, so it stands to reason that they must have ways to mitigate the risk these factors pose. But what are these mitigating factors? What are the costs and benefits of cooperating or cheating in nature? What Dictyostelid traits may have been preadaptations that made it robust against cheaters from the start and allowed it to evolve its cooperative lifestyle? What adaptations may have evolved after the fact to control, exclude, or eliminate cheaters?

These questions and their answers are the focus of this review.

\section{Benefits of the social cycle}

D. discoideum's social stage requires the death of $\sim 20 \%$ of the cells, but there are many benefits that compensate for this cost. When starved, amoebas aggregate into a motile slug. Slugs can move much farther than individual cells can on their own and cross gaps in the soil that amoebas could not (Kuzdzal-Fick et al., 2007). The slug stage thus helps $D$. discoideum aggregates 


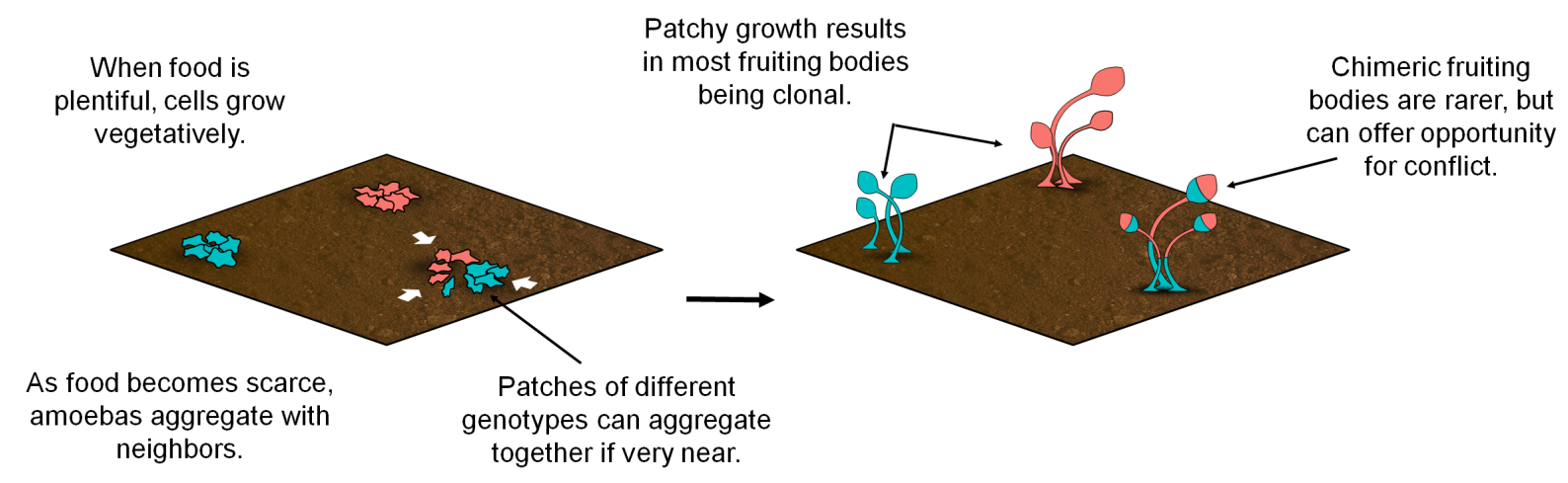

Fig. 2. D. discoideum relatedness in nature. D. discoideum fruiting bodies collected from nature are usually clonal. Clonal fruiting bodies likely result from limited dispersal leading to a patchy distribution of genotypes, such that cells are likely only to interact with clonemates. Millimeter-scale distances between genotypes are likely sufficient to promote high relatedness. Nonetheless, a minority of wild fruiting bodies are chimeric - comprising cells derived from multiple genotypes - and presumably occur where clonal patches of different genotypes intersect.

find suitable environments to form fruiting bodies (Kessin, 2001), and by sloughing off cells in its wake, may also facilitate dispersal into new areas (Kuzdzal-Fick et al., 2007). The slime sheath secreted during slug formation and migration can also protect the amoebas from predation by nematodes (Kessin et al., 1996). Once $D$. discoideum forms a fruiting body and produces a stalk, spores are held aloft where they are more likely to be dispersed to new environments via animal vectors such as small invertebrates like pillbugs, earthworms and nematodes (Huss, 1989; Kessin et al., 1996) or vertebrates like ground-feeding birds, small rodents, salamanders, and bats (Stephenson and Landolt, 1992; Suthers, 1985). Lab studies using Drosophila as a model arthropod vector show that spores are dispersed more effectively when fruiting bodies are intact compared to when they are experimentally knocked over (smith et al., 2014). Alternatively or in addition to dispersal, the stalk may lift the spores above the hazards of the soil (Bonner, 1982; Kessin, 2001). Finally, the social cycle's spore production is clearly beneficial because spores can resist harsh environmental conditions such as long periods of cold, heat, or drought, as well as digestion by animals (Raper, 1984).

\section{Relatedness in nature and how it is generated}

For an altruistic act to evolve, it must confer benefits to relatives. The social cycle in $D$. discoideum is altruistic and has clear benefits, but do the benefits go to relatives? To answer this we need to know the relatedness among $D$. discoideum cells within the same fruiting body in nature. Genetic relatedness is the probability above random expectation that an allele found in one individual is present in another (not, as is sometimes mistakenly assumed, a measure of overall fraction of shared genes.) A relatedness of 0 indicates random mixing and a relatedness of 1 indicates perfect assortment into genetically uniform fruiting bodies. For altruism to evolve, it is necessary (but not sufficient) that relatedness to beneficiaries must be well above zero. In some Dictyostelids like $D$. purpureum and $D$. giganteum there is evidence that co-occurrence of different genotypes in the same fruiting body in nature can occur (Sathe et al., 2010). In D. discoideum, by contrast, relatedness within fruiting bodies found in nature has been estimated using neutral microsatellite markers to be quite high, averaging between 0.86 and 0.975 (Gilbert et al., 2007). This high relatedness could be generated in several different ways.

Oneway that high relatedness can be generated is through spatial structure. If clonal patches of amoebas are typically far enough apart from one another that they do not generally aggregate with cells of other genotypes, then fruiting bodies will usually be clonal (Fig. 2). In fact, when patches are initiated from single cells, only a few millimeters of distance is required to generate high relatedness within fruiting bodies in $D$. discoideum. Furthermore, even adjacent fruiting bodies can be different genotypes (smith et al., 2016). This kind of structure, where patches grow up from single cells and do not mix much, is similar to the single-cell bottlenecks that initiate more conventional multicellular organisms. However, the extreme of a single cell bottleneck is not necessary to generate high relatedness if close relatives disperse together as a group (Gardner and West, 2006; Inglis et al., 2017; Queller and Strassmann, 2012). This may be the case in $D$. discoideum due to its sticky spores that could stick together through dispersal.

Relatedness can also be raised by structured population growth from a genetically mixed group of cells through a process called genetic demixing (Fig. 3) (Queller and Strassmann, 2012). Most outward growth will be from cells at the edge of the group and each sector of the edge will contain few enough cells that random drift can determine which genotype succeeds in that sector. As cells divide and give rise to their neighbors, they form sectors of different genotypes. This phenomenon is well known from bacteria (Gralka et al., 2016; Hallatschek et al., 2007; Hallatschek and Nelson, 2010), and though extensive movement of amoebas might be expected to prevent it, it has been observed in $D$. discoideum grown on agar as well (Buttery et al., 2012). It remains to be determined if this process also occurs in the more natural environment of soil, and if spatial growth of $D$. discoideum in the vegetative stage is important for social evolution in nature.

Another way that high relatedness can be generated is by active processes, wherein individuals specifically take action to interact with genetic relatives (West et al., 2007). This kind of identification and preferential treatment of relatives over nonrelatives is called kin discrimination (Fletcher and Michener, 1987; Strassmann, 2016; Tsutsui, 2004). Some Dictyostelids like D. purpureum have strong kin discrimination and sorting mechanisms (Mehdiabadi et al., 2006; Mehdiabadi et al., 2009; Sathe et al., 2014). In this species different genotypes aggregate together, then sort into two different slugs that 

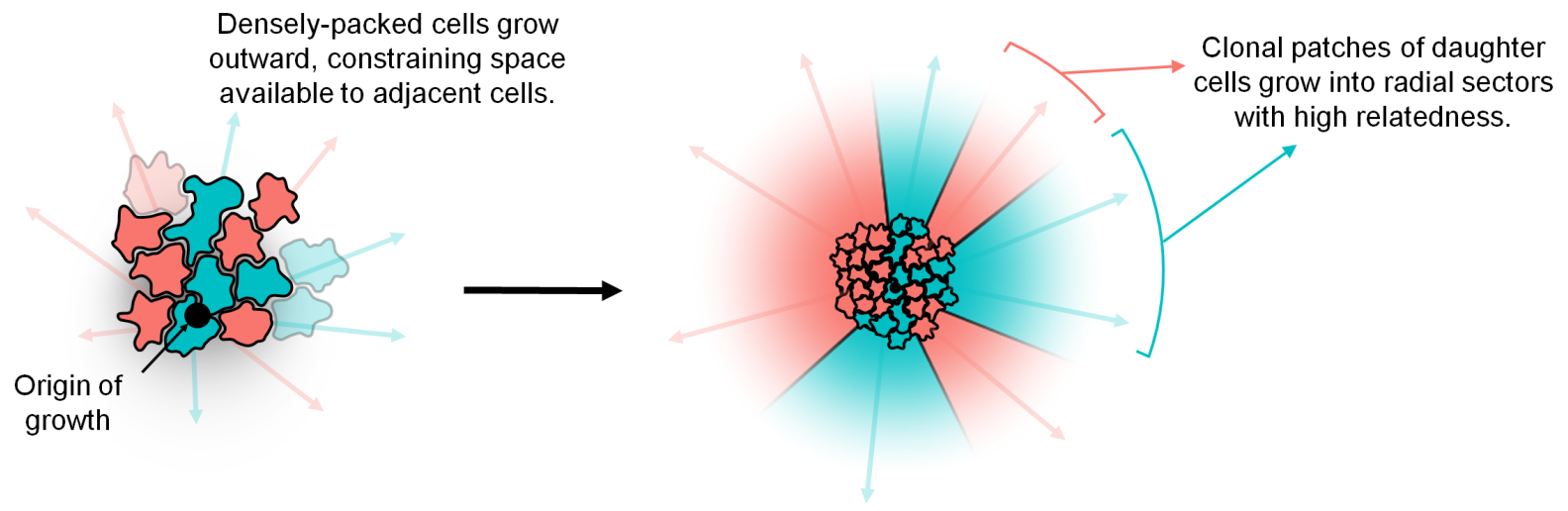

Fig. 3. Genetic demixing in $\boldsymbol{D}$. discoideum. Structured growth of an initially well-mixed (low-relatedness) population can produce patches of high relatedness due to the space constraints imposed on densely-growing cells. Cells on the periphery expand outward into radial sectors of clonal daughter cells. Whether genetic demixing can occur in natural soil is unknown.

go on to make their own mostly clonal fruiting bodies (Fig. 4). $D$. giganteum may also have strong kin discrimination mechanisms that vary by strain, ranging from those that aggregate little with others to those that form clonal clumps within slugs but still fruit together, though sample sizes in these studies were very small (Kaushik et al., 2006; Sathe et al., 2014).

In D. discoideum, the degree of segregation of mixed genotypes into separate fruiting bodies varies among studies and can be quite modest (Flowers et al., 2010; Gruenheit et al., 2017; Ostrowski et al., 2008). Gilbert et al., (2012) mixed co-occurring wild genotypes in equal proportions and found a small but significant increase in relatedness due to kin discrimination. They also found lower levels of relatedness within these chimeras compared to wild fruiting bodies and found fewer clonal fruiting bodies than expected given the frequency of clonal wild fruiting bodies. This indicates that kin discrimination does not fully explain the high relatedness levels found in fruiting bodies in nature.

\section{Costs and benefits of associating with non-relatives}

Overall, relatedness in natural fruiting bodies of $D$. discoideum is high, but $D$. discoideum's aggregative social cycle makes it possible to manipulate relatedness in the lab and study its consequences. Genetic chimeras - aggregations comprised of cells of two or more genotypes - readily form in the laboratory (Strassmann et al., 2000). Chimeras enjoy some benefits, but many associated costs.
The main advantage of chimerism is the potential increase in the size of the aggregate (Foster et al., 2002). Large slugs can move further than smaller slugs, increasing dispersal distance (Foster et al., 2002). An increase in aggregate cell number could also result in taller fruiting bodies, which could increase the chance of dispersal by a passing invertebrate.

The costs of chimerism become apparent when controlling for this size advantage (Fig. 5). Chimeric slugs move shorter distances than clonal slugs when started with the same number of cells (Foster et al., 2002). This could result from competition among the genotypes to avoid the pre-stalk region located in the front of the slug and move towards the posterior pre-spore region. A mechanism for this could be incompatibility between allotypes of the tgr recognition system (see below) that reduces slug movement by affecting adhesion of cells within the slug (Gruenheit et al., 2017; Hirose et al., 2015).

Perhaps the biggest fitness consequence to cells in a chimera is the potential for cheating or being cheated (Fig. 1). In chimeras, the benefits of the social cycle may not distribute equally between all of the genotypes involved. Some genotypes could contribute less towards stalk production and make more spores. We define this as cheating for $D$. discoideum. For example, if cells of genotypes $A$ and $B$ form a chimeric aggregate at a 50:50 ratio then, in the absence of cheating, half the spores in the resulting fruiting body should belong to genotype $A$ and half to $B$ (Fig. 6A). However, if $A$ cheats $B$, we may find that $60 \%$ of the spores are genotype $A$ while only $40 \%$ are genotype $B$.

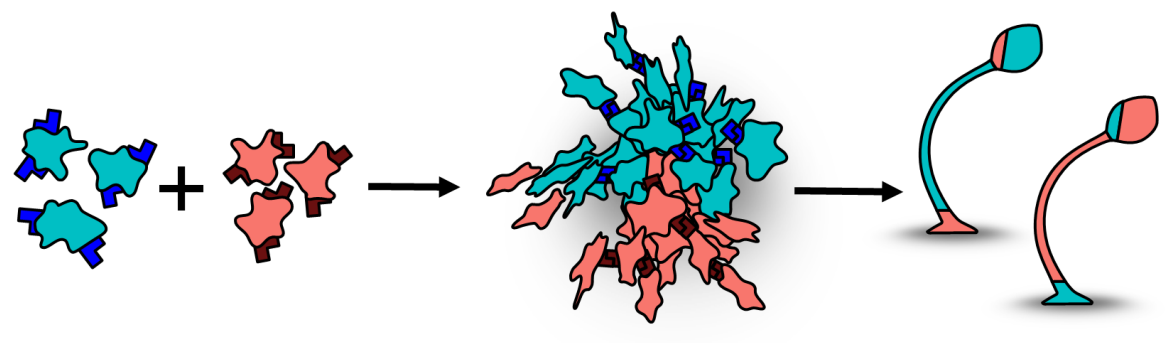

Allorecognition receptors may increase relatedness by causing genotypes to partially preferentially aggregate with themselves.

Fig. 4. Allorecognition in Dictyostelids. There is evidence for varying degrees of self-sorting among Dictyostelid species. Cells bearing the same alloreceptors preferentially bind to one another in an aggregate and thus may increase relatedness (and thereby reduce the opportunity for cheating) within developing fruiting bodies by sorting kin into distinct regions of the aggregate. 

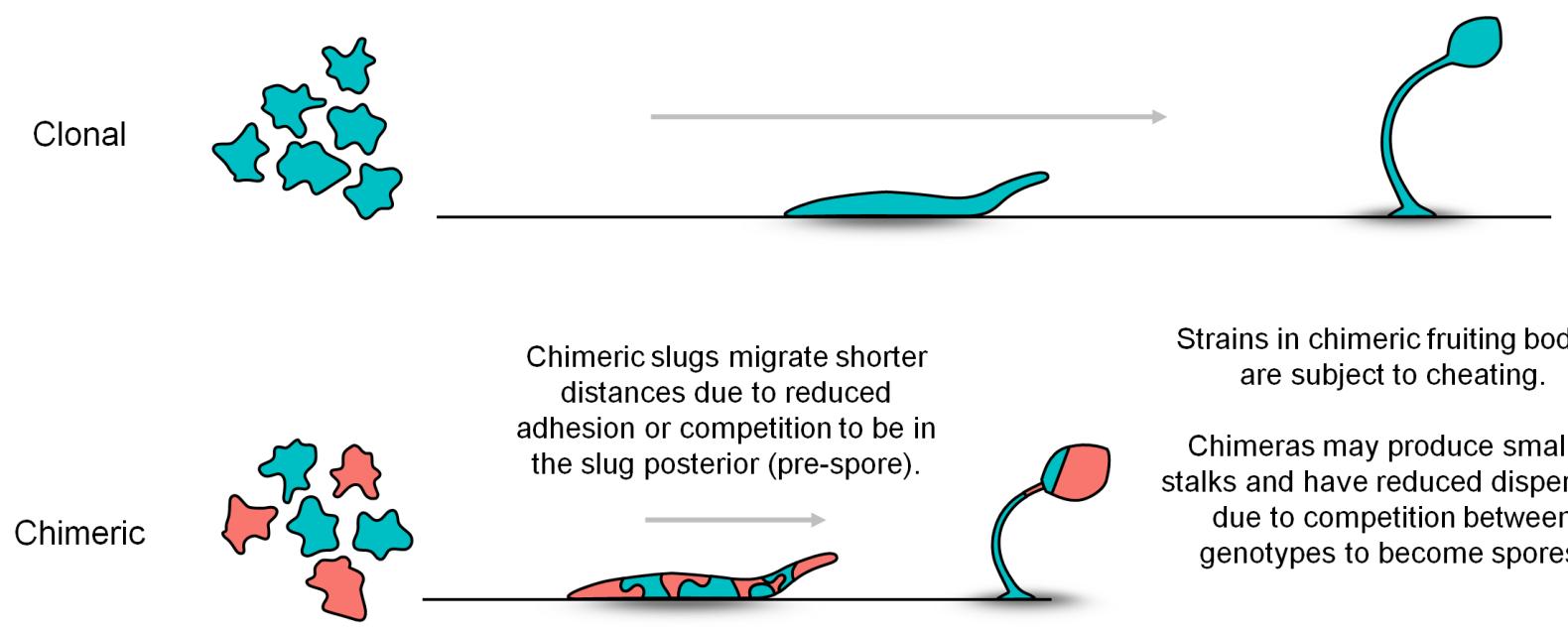

Strains in chimeric fruiting bodies are subject to cheating.

Chimeras may produce smaller stalks and have reduced dispersion due to competition between genotypes to become spores.

Fig. 5. Costs of chimerism in $\boldsymbol{D}$. discoideum. While forming a chimera may sometimes be beneficial if it results in a larger aggregate, chimeric slugs are less motile than clonal slugs of the same size, which may result from conflict between genotypes within the slug. Chimeric fruiting bodies also are subjected to the risk of being cheated upon, and may produce smaller stalks than clonal fruiting bodies.

There are three forms of cheating-related spore-stalk allocation strategies: fixed, facultative, and obligate (Fig. 6) (Buttery et al., 2009; Strassmann and Queller, 2011). Fixed cheating occurs when cells of one genotype inherently invest more into spore production and less into stalk production than cells of another genotype (Fig. 6B). On their own the two genotypes will differ in fruiting body morphology. When these two genotypes form a chimera, one genotype will be overrepresented in the spores even though it is not acting any differently than it would on its own. Variation in clonal allocation could be a result of natural selection on other traits favoring different optimal spore-stalk allocation, but it could also have evolved for the purpose of cheating advantage when in chimeras.

In contrast, facultative cheaters change their behavior in response to the presence of another genotype, and can be further partitioned into self-promoting and coercive cheaters (Fig. 6C) (Buttery et al., 2009). Self-promotion occurs when a genotype selfishly increases its spore investment in a chimera. Coercion occurs when the partner genotype is coerced to increase its stalk investment in a chimera. For example, consider genotypes $A$ and $B$ with the same clonal spore-stalk allocation of 80:20. If $A$ cheats through self-promotion then A's allocation could change to 90:10 in chimeras, whereas if $A$ cheats through coercion then it could force B's allocation to change to 70:30.

Obligate cheaters, or social parasites, are another form of cheater that cannot develop properly on their own and must have a victim to exploit (Fig. 6D). These cheaters threaten multicellularity itself because if they grow and spread they could eventually eliminate those able to form stalks, leading to their extinction since $D$. discoideum can only make hardy spores with the formation of stalked fruiting bodies. Obligate cheaters evolve readily in the lab (Ennis and Sussman, 1975; Kuzdzal-Fick et al., 2011; Santorelli et al., 2008) but they are likely rare or nonexistent in nature because they have not been found in $D$. discoideum despite the screening of thousands of natural isolates (Gilbert et al., 2007).

Cheating is common in chimeras; one genotype often dominates the other genotype and produces more spores (Strassmann etal., 2000). There is evidence for both fixed and facultative strategies in wild clones (Buttery et al., 2009). Variation in fixed cheating strategies partially explains the linear hierarchy of exploitation by genotypes (Buttery et al., 2009; Fortunato et al., 2003), but the exact extent of exploitation by a genotype also depends upon its competing partner genotype in the chimera, consistent with some occurrence of facultative cheating (Buttery et al., 2009).

There are two other kinds of evidence consistent with facultative cheating. First, since there is less benefit to one's own spores by investing in stalk in chimeras, facultative cheating via self-promotion would predict that chimeras should produce more spores. There is evidence for an increase in overall spore production in chimeras (Buttery et al., 2009) but the evidence is ambiguous about whether this results in shorter stalks. Some studies show that chimerism had no significant effect on fruiting body morphology, implying there was no reduction in stalk height (Foster et al., 2002) or showed no consistent pattern in change in stalk height (Votaw and Ostrowski, 2017), whereas another study reports that chimerism results in significant change in fruiting body architecture (Buttery et al., 2009). These inconsistencies might be because stalk height is much harder to measure and more variable than spore investment. Clearly more work is needed on this important topic.

Second, there is some evidence that cheating is frequency dependent (Madgwick et al., 2018), such that the rarer the genotype is within a chimera, the more it cheats. This provides more evidence for facultative cheating, where spore-stalk investment is modulated on the basis of relatedness to the group. It makes sense adaptively because a rare genotype that makes stalk cells will mostly be benefiting the other genotype (Madgwick et al., 2018). However, another study reports no or weak frequency dependence depending on the genotypes examined (Buttery et al., 2009).

\section{Genes for cheating}

D. discoideum's rich history as a model system allows one to identify genes that control cheating behavior. Restriction enzyme mediated integration (REMI) is a powerful tool for gene identification, wherein gene knock-outs are created by inserting DNA fragments into the genome. Ennis et al., (2000) generated a large 
A

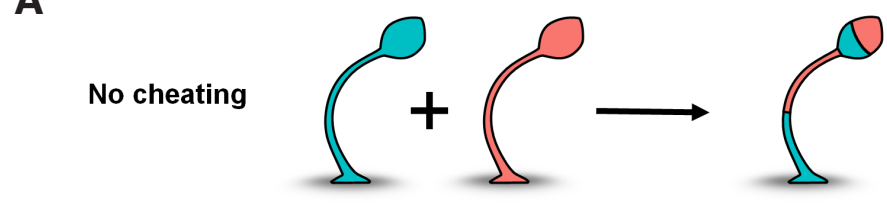

B

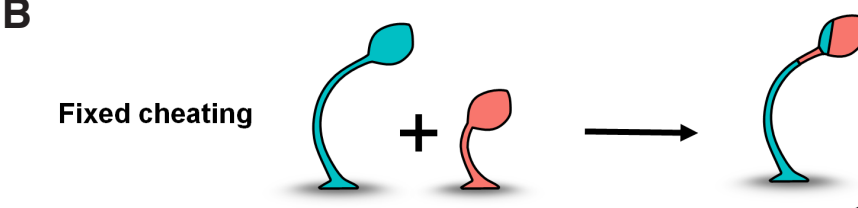

C
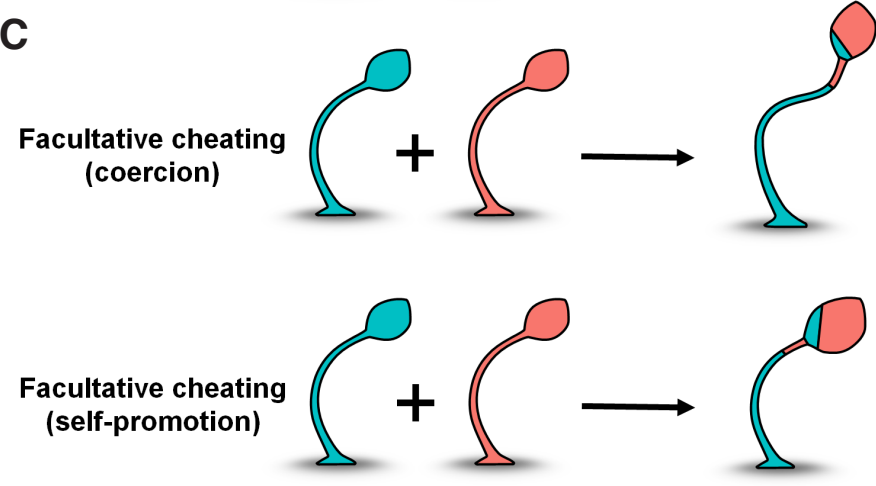

D

Obligate cheating (social parasitism)
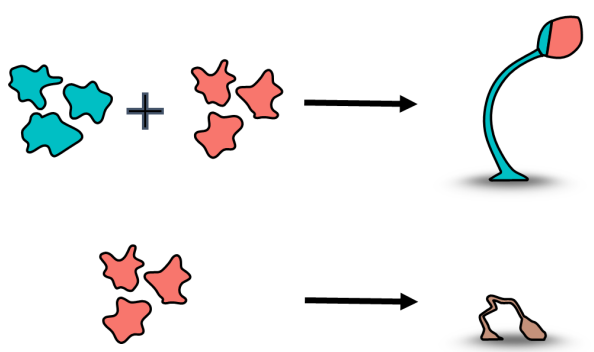

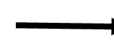

Each genotype contributes equally to spore and stalk cells.

Fixed cheaters have reduced stalk investment both when growing clonally and in chimeras.

Coercive facultative cheaters force other genotypes to increase stalk investment (or reduce spore investment) in chimeras.

Self-promoting facultative cheaters invest normally in stalk formation when growing clonally, but reduce stalk investment (or increase spore investment) in chimeras.

Social parasites depend on the presence of cooperating genotypes to fruit. Pleiotropic effects give obligate cheating genotypes low fitness while clonal.

Observed in experimental evolution experiments but not in wild populations.
Fig. 6. Cheating strategies in $D$. discoideum. (A) In the absence of cheating, two genotypes that aggregate together in a 50:50 ratio will each contribute half of the resulting fruiting body's stalk and half of its sorus. (B) Fixed cheaters produce a higher spore:stalk ratio when grown clonally or in a chimera. These strategies may or may not have evolved due to the social benefits of cheating in chimeras. (C) Facultative cheaters take advantage of other genotypes in a chimera by either forcing other genotypes to reduce their spore:stalk ratio (coercion) or increasing their own spore:stalk ratio (self-promotion). (D) Obligate cheaters depend on the presence of other genotypes to fruit. They have been observed in experimentally evolved populations in the laboratory never isolated in nature. pool of REMI mutants that were each randomly disrupted for a single gene function, then selected for preferential spore production. They identified a mutant called $\operatorname{cht} A$ (a $f b x A$ knockout) that is an obligate social cheater, which is able to cheat in chimeras but is developmentally deficient and produces few spores when grown clonally.

Using a similar approach, Santorelli et al., (2008) subjected pools of REMI mutants through several cycles of spore production, but obligate cheaters were excluded by only considering clones capable of normal fruiting body development when clonal. This resulted in the identification of 167 candidate cheater genes that increased in frequency. On characterizing a smaller subset of 31 confirmed cheater genes, they found that $45 \%$ of these genes were not significantly different from wild type in their sporulation efficiency when grown clonally. These mutants are facultative cheaters that are able to produce more than their share of spores when in chimera but cooperate normally when clonal.

One such facultative cheater is chtB (Santorelli et al., 2013). A chtB mutant is able to form a normal fruiting body when alone, but upon mixing in equal proportion with a wild genotype, cht $B$ mutants contribute nearly $60 \%$ of the spores. This mutant shows no trade-offs in general morphology, spore production, or germination efficiency. Similarly, chtC mutants are also facultative cheaters that cheat by affecting pre-stalk differentiation and show no trade-off with general morphology or spore production (Khare and Shaulsky, 2010). Determining the reasons why mutations that disrupt such gene functions have not spread in wild populations despite an apparently cost-free cheating strategy is an interesting avenue of future research.

\section{Power}

Each cheater gene must use some particular mechanism to ensure that it gets into spores. The number and functional diversity of such genes suggests that there are many such levers of power (Santorelli et al., 2008). But there are also some general environmental factors that affect the power to win in chimeras and, if cheating is important in nature, amoebas will likely have evolved to exploit these levers of power as well.

In animals, contests and fights are often won by the largest individuals or those in the best condition. Consistent with this, $D$. discoide umcells fed glucose are more likely to become spores over those starved of glucose (Castillo et al., 2011; Leach et al., 1973; Thompson and Kay, 2000). Similarly, cells weakened with acid are less likely to become spores (Fig. 7) (Castillo et al., 2011). There is a possibly related effect of stage of the cell cycle, where cells 
Fig. 7. Power impacts cell fate in $\boldsymbol{D}$. discoideum. Power partially determines the fate of cells within a developing fruiting body, such that more powerful cells are more likely to become spores while less powerful cells are forced to become stalk cells. Cells experimentally weakened with acid or starvation are more likely to become stalk cells. Cells late in the cell cycle are larger and have more resources than cells that have recently divided, and thus tend to differentiate into spores upon entering the social cycle.

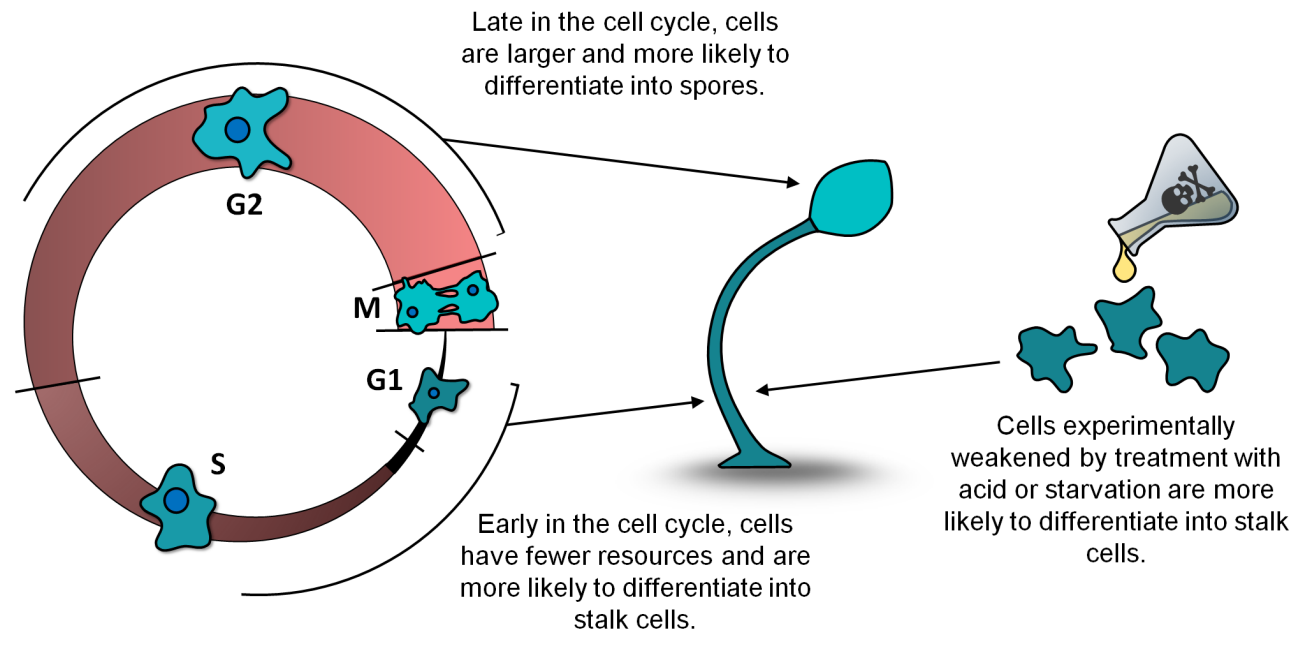

Late in the cell cycle, cells re larger and more likely to differentiate into spores.

in the period shortly after cell division are more likely to become stalk than those that have had more growth and command more resources (Fig. 7) (Araki et al., 1994; Azhar et al., 2002; Gomer and Firtel, 1987; Gruenheit et al., 2018).

However, the first cells to starve, which should have fewer stored nutrients, tend to become spores (Kuzdzal-Fick et al., 2010). One explanation is that although resource-rich cells have an advantage, this could be overcome by cells that have time to prepare their "weapons" and become superior competitors (Castillo et al., 2011; Queller and Strassmann, 2018; Strassmann and Queller, 2011). It is interesting from an evolutionary perspective that amoebae would join a signaler of starvation that is itself taking the selfish role and expecting the later joiners to become the altruistic stalks.

These results are consistent with cells using whatever environmental advantage they can to be among the $75-80 \%$ to become spores. It has been argued that competition is a sufficient explanation of the altruistic behavior in $D$. discoideum, that it is a pure game of power and individual selection, rather than kin selection to help relatives (Atzmony et al., 1997). In this view, all cells try to become spores and the losers are forced to form stalk.

However, kin selection and individual selection make different predictions about the relative strength of purifying selection in genes expressed in prespore and prestalk cells, with the evidence supporting kin selection (Noh et al., 2018). The strength of purifying selection on a gene depends upon the fraction of individuals that express it (Van Dyken and Wade, 2010). Since only 1 in 5 cells become stalk, purifying selection against mildly deleterious mutations will be four times less effective in prestalk cells than prespore cells. Thus, individual selection predicts that prestalk genes should be at least four times more polymorphic than prespore genes. Under kin selection, all selection on prestalk cells is mediated through indirect selection on the related spore cells. Accounting for the observed levels of relatedness in fruiting bodies $(0.86-0.97$ (Gilbert et al., 2007)), the levels of purifying selection in prestalk genes should be only $1.03-1.17$ times as variable in the prespore genes. The observed relative strength of purifying selection is consistent with the prediction from kin selection.

Even if power could fully explain which cells lose, it cannot explain the subsequent behavior of these losers. They build a very complex stalk, and this behavior can be heritable only via related spores because stalk cells do not reproduce. Kin selection and power can of course operate together, with power accounting at least partly for which cells become stalk cells but kin selection explaining their ability to stop competing and act instead to contribute to spore success.

\section{Cooperation is maintained by control of cheaters}

In $D$. discoideum, the altruistic behavior of some cells can be exploited by cheater mutants. Though exploitation is unlikely to happen if relatedness is high and cheaters are forced to primarily interact with themselves, $D$. discoideum nonetheless has mechanisms that can control cheating and prevent cheaters from taking over a population including allorecognition, pleiotropy, and evolved resistance.

\section{Control of cheating by high relatedness}

The very high relatedness within natural fruiting bodies should act as a strong control on cheating because different genotypes will usually be in different fruiting bodies. In an experimental demonstration of how high relatedness can control cheating, relatedness above 0.25 prevented an obligate social cheater called cht $A$ from increasing in frequency when mixed with its non-cheating ancestor AX3 (Gilbert et al., 2007). Similarly, low relatedness can select for cheater mutants which conversely indicates the importance of high relatedness for controlling them. When 24 initially clonal lines of $D$. discoideum were evolved at low relatedness (new clones that emerged by mutation were randomly mixed among all the others in each social generation) for 31 social cycles or about 290 cell divisions, clones in the resulting populations significantly cheated their ancestor and included many obligate cheaters (Fig. 8) (Kuzdzal-Fick et al., 2011). These examples show that low relatedness allows the spread of both facultative and obligate cheaters.

\section{Control of cheating by allorecognition}

Cooperation can be stabilized when cooperators direct their cooperation towards those that have a shared specific gene for cooperation and not to those that lack it, called greenbeard recognition (Fig. 4) (Dawkins, 1976; Hamilton, 1964a; Hamilton, $1964 b)$. This is a mechanism by which alleles directly recognize 

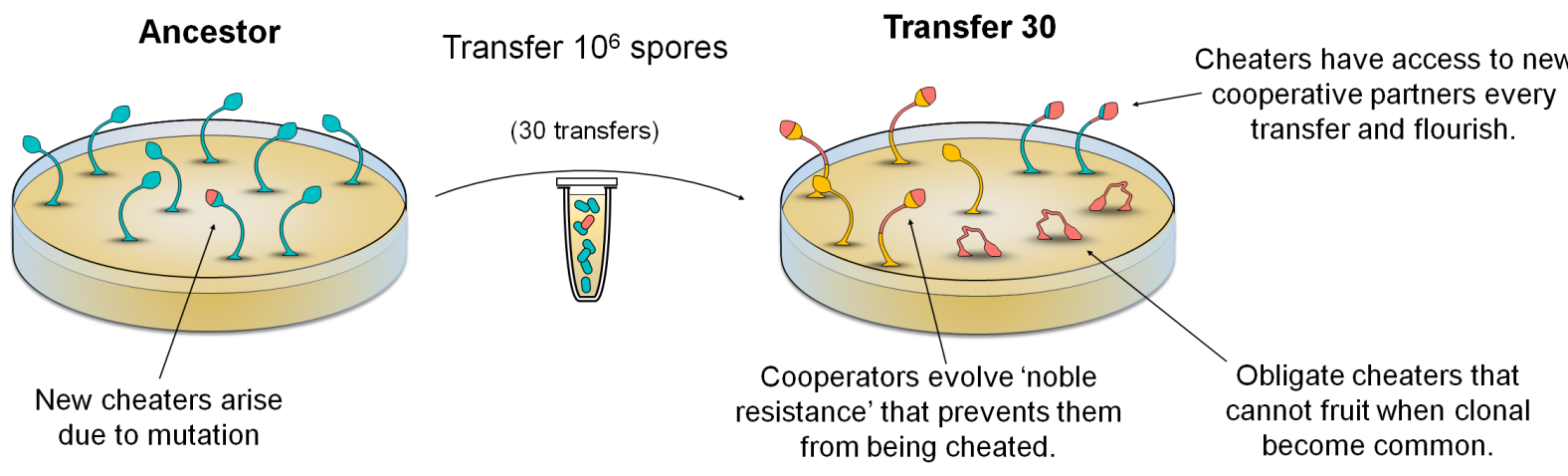

Fig. 8. Relatedness affects evolution of cheaters in $\boldsymbol{D}$. discoideum. Kuzdzal-Fick et al., experimentally evolved replicate lines of D. discoideum under treatments enforcing low relatedness. Transfers were performed using $10^{6}$ spores gathered from across the plate, effectively mixing the population each transfer. Cheater mutants were repeatedly exposed to new partners to exploit and so prospered. Obligate cheaters incapable of fruiting on their own readily evolved. Eventually, the pressure exerted by cheaters caused other genotypes to evolve 'noble resistance' - these strains could resist cheating without being cheaters themselves.

one another, different from genetic relatedness which is based on the probability that both individuals share the gene for cooperation.

One set of genes that fits these criteria are a pair of tightly linked, highly variable cell adhesion genes of $D$. discoideum called tgrB1 and $\operatorname{tg} \mathrm{rC1}$, which are essential for development (Benabentos et al., 2009; Gruenheit et al., 2017; Hirose et al., 2011; Hirose et al., 2015). These genes encode a ligand-receptor pair anchored in the cell membrane (Hirose et al., 2017). As would be expected for a functioning allorecognition system, they are highly polymorphic, with the highest levels of both allelic and total sequence variation in the $D$. discoideum genome. Their sequence dissimilarity and binding affinity correlates with the degree of genotype segregation into separate fruiting bodies (Benabentos et al., 2009; Gruenheit et al., 2017). This strongly suggests that the tgrgenes are responsible for allorecognition. Furthermore, all genotypes aggregate together but those with sufficiently different tgr genes then segregate into distinct clumps within the aggregate and then into separate slugs (Gruenheit et al., 2017; Hirose et al., 2011), although slugs may later fuse to form chimeric fruiting bodies (Ho and Shaulsky, 2015). Incompatible tgr genes can also prevent obligate social cheaters from invading because cheaters that lack the matching Tgr proteins are excluded from the final fruiting body (Ho et al., 2013). Even if $t g r$ genes result in incomplete sorting in fruiting bodies, earlier sorting within the aggregate may prevent cheating if cells decide whether to become spore or stalk based on their very close neighbors. Fusion at the slug stage may not lead to much cheating if, as some evidence suggests, cheaters act primarily at earlier stages (Ho and Shaulsky, 2015) and such fusion might enhance fitness through larger fruiting bodies and better dispersal. Thus, these greenbeard genes may function more to limit exploitation within fruiting bodies than to cause sorting into kin groups in the fruiting bodies.

\section{Control of cheating by pleiotropy}

When a gene or set of tightly linked loci encoding a cooperative behavior also has another essential function, cooperation can be maintained because cheaters (those that lack the gene) cannot survive. This is called pleiotropy, when a single gene influences multiple phenotypes. In general, pleiotropy can hamper the evolution of a trait because selection on that trait also affects other traits.

In D. discoideum, several genes cause cheating when they are knocked out, but also have an essential function. For example, the obligate social cheater mutant $c h t A$ pays a pleiotropic cost: it cannot make spores on its own and chimeric fruiting bodies that contain more chtA produce fewer spores (Ennis et al., 2000; Gilbert et al., 2007).

Another example is the gene $\operatorname{dim} A$, which is required to receive the signaling molecule DIF-1 that causes differentiation into prestalk cells. Absence of this gene, and thus blindness to the DIF-1 signal, should allow cells to avoid becoming stalk cells. However, cells lacking this gene are excluded from becoming spores as well by an unknown mechanism. Here, cheating on prestalk cell production yields an even greater reduction in spores so it should be selected against in nature (Foster et al., 2004).

A third example of pleiotropy maintaining cooperation by preventing the evolution of cheaters are the $\operatorname{cs} A$ mutants, which lack functional gp80 adhesion proteins. Cells with this mutation cheat their ancestor AX4, presumably because during the slug stage they slide to the prespore region at the back of the slug. However, these mutants can only act as a cheater when grown on agar, but not the more realistic substrate of soil (Queller et al., 2003).

\section{Control of cheating by evolved resistance}

Cooperators can evolve to resist cheaters without evolving to become cheaters themselves, even when cheaters can evolve in response (Hollis, 2012; Khare et al., 2009; Levin et al., 2015). Khare et al., (2009) found that introducing a cheater into a randomly mutated population of $D$. discoideum selected for mutants that resisted cheating but did not cheat the ancestral strain or the original cheater. In addition, Hollis (2012) mixed two genotypes, one which strongly cheated the other, and found that the non-cheater evolved resistance to cheating. These studies show that cooperators can evolve to resist cheaters without cheating them in turn.

Levin et al., (2015) tested if evolved obligate social cheaters cheated on their contemporaries in addition to their ancestors. They found that the contemporaries resisted the cheaters without themselves cheating. This shows that resistors can evolve in populations where obligate cheaters had already evolved (Fig. 8 ), but before the cheaters have swept through the population. This indicates that the evolution of resistance to cheating can be quite rapid. 
Evolved resistance to cheating could in turn select for stronger cheating in a positive feedback loop, called an arms race or red queen dynamics (Queller and Strassmann, 2018). This would be similar to the dynamics between hosts and pathogens, where pathogens continually evolve to better infect their hosts while their hosts evolve in response to resist the pathogens.

\section{Relevance of cooperation and cheating for $D$. discoideum}

Lab studies on $D$. discoideum have advanced our knowledge about many aspects of cheating behavior, such as its genetic basis and the various mechanisms that allow for its control. However, the relevance of this behavior in nature has been questioned. Since we cannot observe these behaviors in the wild, we may overinterpret such responses in the lab.

Apparent cheating could be a result of trade-offs associated with other life-stages. Hence, what appears to be an outcome of social interaction could be due instead to selection on other non-social traits (Tarnita, 2017). One study suggests that unequal spore numbers in the fruiting body may not translate into unequal social success because spore production trades off with spore viability (Wolf et al., 2015). Natural variation between genotypes in spore production is negatively correlated with their spore size, which in turn is correlated with spore viability. Genotypes that produce more spores in chimeras may sometimes do so by producing smaller, less viable spores, and hence gain no cheating advantage. However, another study found no correlation between spore production and spore viability when averaged by genotype (Votaw and Ostrowski, 2017).

Some studies argue that there is a trade-off between staying a vegetative cell and becoming a spore (Dubravcic et al., 2014; Tarnita et al., 2015). "Loner" amoebas that do not join the aggregate remain viable and benefit from a head start over cells that have become spores and thus need time to germinate into vegetative cells (or alternatively have been dispersed away). Thus genotypes that appear to be victims of cheating because they produce fewer spores in chimeric fruiting bodies could instead simply be strains that produce more loner cells. However, nothing is known about the frequencies and viabilities of loner cells in nature to test this proposed trade-off.

Importantly, insights from population genomics and molecular evolution suggest that cheating and conflict in chimeras are not just laboratory artifacts. Conflict can be an exceptionally strong and persistent selective pressure driving evolutionary arms races (Dawkins and Krebs, 1979; Queller and Strassmann, 2018; Van Valen, 1973). If cheating occurs in nature for $D$. discoideum, then it may cause resistance to cheating to evolve, as has been observed in the lab (Hollis, 2012; Khare et al., 2009; Levin et al., 2015). This could lead to an escalating arms race in which new cheating genes and new resistance genes sweep through the population. This in turn would lead to increased adaptive divergence for the genes involved. Another possibility is that there is negativefrequency dependence to cheating as has also been observed in a laboratory setting (Madgwick et al., 2018). This means that cheaters prosper only when they are in low numbers. This would lead to increased non-synonymous variation within species and decreased non-synonymous divergence between species for the genes involved. However, if cheating behaviors are not important and do not experience strong adaptive selection, then their pat- terns of sequence variation should be similar to other genes in the genome, influenced primarily by drift and purifying selection.

Ostrowski et al., (2015) analyzed variation between and within species sequence in 160 candidate cheater/cooperation genes identified from the Santorelli et al., (2008) REMI mutant study. The signatures in sequence variation were most consistent with greater-than-normal negative-frequency dependent selection, acting to maintain both cheaters and cooperators as a balanced polymorphism (Ostrowski et al., 2015). This finding is consistent with the laboratory finding that cheating is frequency dependent (Madgwick et al., 2018).

Noh et al., (2018) used RNA-seq to identify a second set of cooperation/cheater genes by screening for genes that change expression in chimeric mixtures of two genotypes. It is in this exact context that cheating is likely to be adaptive, and hence if any genes function specifically in cheating or resistance to cheating, these are excellent candidates. They identified 79 genes that significantly differed in their expression in chimeras compared to controls. These genes show elevated rates of adaptive evolution $\alpha$ compared to the genomic background. This is consistent with escalating arms race conflict leading to high rates of adaptive evolution in these genes.

It is not clear why one set of genes showed excess balancing selection and the other showed excess adaptive fixations. That said, the gene sets are quite different; the first study used REMI mutants selected for cheating while the second set used naturally expressed genes that may include resistance genes. In any case, both these studies provide strong evidence for the historical importance of cheating in the wild. Several other studies strengthen this claim. First, mutation accumulation experiments show that random mutations often tend to decrease cheating ability, which is consistent with cheating being a fitness component in nature, although the effect was not strong (Hall et al., 2013). Second, the presence of allorecognition systems such as the tgrgenes indicates that avoiding non-kin that might harm or cheat is important for $D$. discoideum. Finally, there are other apparent adaptations that seem consistent with cheating in the wild: reduced slug migration in chimeras (Foster et al., 2002), allocating more to spores when in chimera (Buttery et al., 2009) and even more for minority genotypes in chimeras (Madgwick et al., 2018). Although non-adaptive explanations could be possible, such complex responses make sense if cheating when with non-relatives and cooperating when with relatives actually conferred a fitness benefit in the wild.

\section{Other domains of cooperation and conflict}

D. discoideum's unique social cycle makes it useful for studies on the evolution of cooperation and conflict, and it also engages in cooperation and conflict in other parts of its life cycle.

\section{The sexual cycle}

The formation of the macrocyst in $D$. discoideum's sexual cycle involves uniquely social processes (Fig. 9). When amoebas are starving under wet, phosphorus-poor conditions, two individuals of different mating types can fuse into a diploid zygote (Bloomfield, 2013; Bonner, 1967; Kessin, 2001). The zygote emits a cAMP signal that draws other cells in the vicinity towards it. Many of the attracted peripheral cells are consumed by the zygote for nutrition, and the rest construct a cellulose wall around the aggregate 


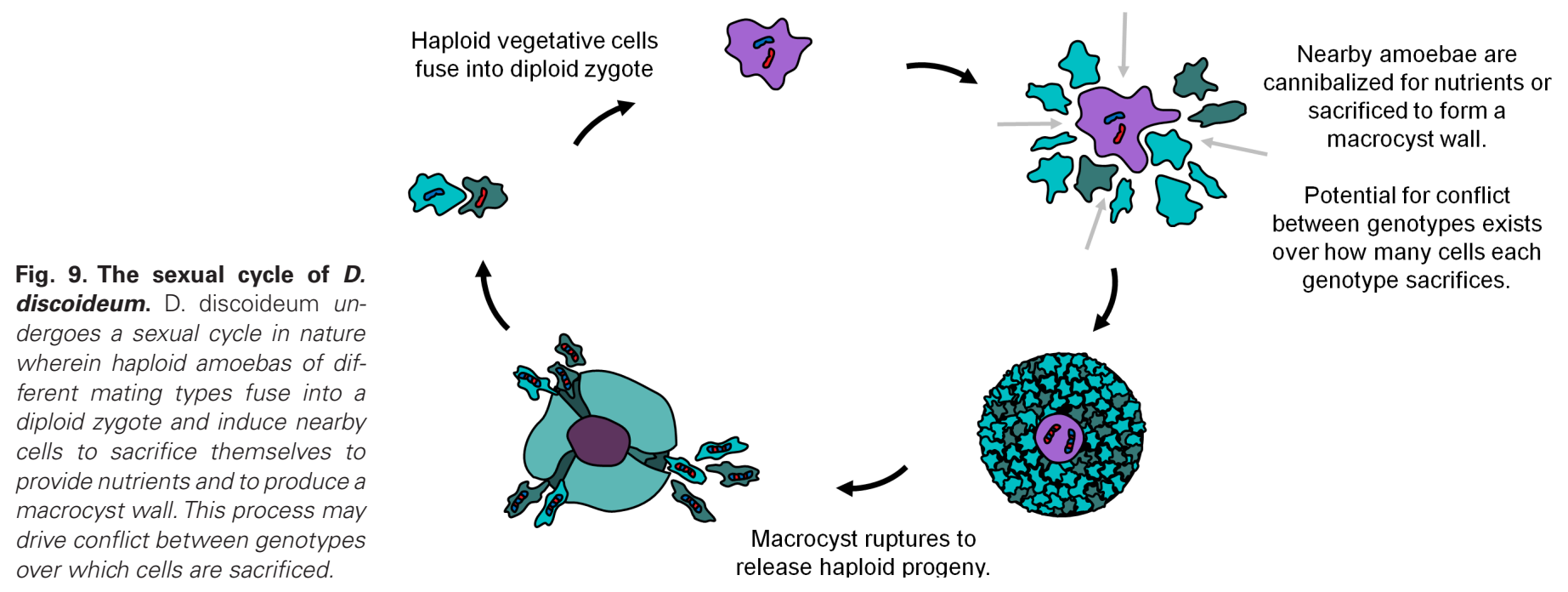

before they are themselves consumed. Following this, the zygote undergoes recombination, crossing over, and meiosis, forming many recombinant haploid cells.

The sexual cycle involves an act of altruism by the peripheral cells, as they give up their lives. It is unlikely that these cells are simply victims because they actively further the success of the zygote by building the macrocyst wall around it, but their sacrifice does potentially set the stage for social conflict over which cells are sacrificed. For example, each mating type might prefer to evade consumption to some degree and allow cells of the other mating type, its non-relatives, to provide most of the sacrifices necessary to construct the macrocyst (Douglas et al., 2017). One way this could be measured is if a genotype produces a disproportionate number of macrocysts - a rare genotype should prefer more macrocysts be made because the common genotype will make up most of the food, while a common genotype should prefer fewer for the same reason. However, when one genotype is rare it usually does not cause disproportional investment in macrocysts, which instead appear to be limited by partner availability (Douglas et al., 2017).

Sexual reproduction happens often in $D$. discoideum in the wild as evidenced by high recombination rates (Flowers et al., 2010), but it is difficult to get the full process to occur in a laboratory setting (Kessin, 2001). Despite this, major advances have been made in recent years. The sex-determining locus is known and the presence of three different mating types has been confirmed (Bloomfield et al., 2010). A recent study has revealed an interesting mode of triparental inheritance in lab crosses involving more than two gametes, where two parents contribute to the nuclear genome and the mitochondrial genome comes from the third (Bloomfield et al., 2018). Much is still unknown about the sexual cycle, and it provides a rich area for future study.

\section{Cooperative predation}

A recent study suggests that vegetative growth in $D$. discoideum while preying on bacteria might not be asocial, but instead may involve cooperative predation (Rubin et al., 2019). They found that $D$. discoideum growth is positively correlated with amoeba density, and mutants that grow poorly on live bacteria can be rescued by the presence of wild-type amoebas and synergistic mutants. They suggest this is due to the secretion of diffusible factors by wild-type cells that facilitates mutant growth, though the molecule mediating such an interaction has not yet been identified. Another study showed that $D$. discoideum plated in the presence of high densities of the bacterium Escherichia coli could proliferate only when plated at high densities themselves (DiSalvo et al., 2014). More work in this direction could clarify the role of cooperative predation in $D$. discoideum.

\section{Cooperation and conflict between species}

In addition to being a valuable model organism for studying cooperation and conflict within a single species, $D$. discoideum's interactions with symbiotic bacteria can also be informative about cooperation and conflict between species. Roughly one third of wild-collected $D$. discoideum strains harbor bacterial endosymbionts belonging to the genus Burkholderia, with which they have a complex relationship involving both cooperation and conflict (DiSalvo et al., 2015). Burkholderia-infected D. discoideum suffer some toxicity but can carry other more edible species of bacteria through their social cycle, which improves $D$. discoideum's fitness when sorus contents are dispersed to environments without suitable food (Brock et al., 2011). The extent to which D. discoideum and Burkholderia spp. are friends or enemies is likely to depend on strain-to-strain variation and environmental context. In addition, $D$. discoideum is known to associate more transiently with a host of other bacterial taxa, including both edible and inedible strains (Brock et al., 2018). Just as D. discoideum's management of conflict with cheaters within its own species can inform us about the benefits and constraints of multicellularity at large, the ways $D$. discoideum and Burkholderia interact with and evolve against this larger microbiome can model the important relationships between multicellular eukaryotes and their bacterial microbiotas in general.

\section{Conclusion}

Clearly, $D$. discoideum has provided profound insights into both the proximate (how) and ultimate (why) explanations for the evolution of cooperation and control of conflict. This has been facilitated by the fusion of two rich fields: cutting-edge molecular techniques and social evolution theory. However, there are many questions that are yet to be fully explored and resolved. Why is there a kin recognition system if it only weakly increases relatedness? How important is frequency dependence for determining 
cheating behavior? What conflicts occur in the sexual stage, and how do they manifest? How is cooperation between non-relatives enforced in the sexual stage? What are the relationships between $D$. discoideum and members of its microbiome, and how do these relationships evolve? Future work will address these questions and many others, as we still have much to learn from $D$. discoideum.

All figures by Tyler Larsen, licensed under creative commons CC BY-SA.

\section{References}

ARAKI T, NAKAO H, TAKEUCHI I, MAEDA Y (1994). Cell-cycle-dependent sorting in the development of Dictyostelium cells. Dev Biol 162: 221-228.

ATZMONYD, ZAHAVIA, NANJUNDIAHV (1997). Altruistic behaviour in Dictyostelium discoideum explained on the basis of individual selection. Curr Sci 72: 142-145.

AZHARM, KENNADYP, PANDE G, ESPIRITUM, HOLLOMANW, BRAZILLD, GOMER $\mathrm{RH}, \mathrm{NANJUNDIAH} \mathrm{V} \mathrm{(2002).} \mathrm{Cell} \mathrm{cycle} \mathrm{phase,} \mathrm{cellular} \mathrm{Ca2}+$ and development in Dictyostelium discoideum. Int J Dev Biol 45: 405-414.

BENABENTOS R, HIROSE S, SUCGANG R, CURK T, KATOH M, OSTROWSKI EA, STRASSMANN JE, QUELLER DC, ZUPAN B, SHAULSKY G, KUSPAA (2009). Polymorphic Members of the lag Gene Family Mediate Kin Discrimination in Dictyostelium. Curr Biol 19: 567-572.

BLOOMFIELD G (2013). Sex in Dictyostelia. In Dictyostelids: Evolution, Genomics and Cell Biology (Eds M Romeralo, S Baldauf, and R Escalante). Springer Berlin Heidelberg, Berlin, Heidelberg, pp. 129-148.

BLOOMFIELD G, PASCHKE P, OKAMOTO M, STEVENS TJ, URUSHIHARA H (2018). Triparental inheritance in Dictyostelium. bioRxiv.

BLOOMFIELD G, SKELTON J, IVENS A, TANAKAY, KAYRR (2010). Sex Determination in the Social Amoeba Dictyostelium discoideum. Science 330: 1533-1536.

BONNER JT (1982). Evolutionary Strategies and Developmental Constraints in the Cellular Slime Molds. Am Nat 119: 530-552.

BONNER JT (1967). The cellular slime molds. Princeton University Press, Princeton, NJ. BOURKE A (2011). Principles of Social Evolution. Oxford University Press, Oxford.

BOURKE AF, FRANKS NR (1995). Social evolution in ants. Princeton University Press, Princeton, NJ.

BROCK DA, DOUGLAS TE, QUELLER DC, STRASSMANN JE (2011). Primitive agriculture in a social amoeba. Nature 469: 393-396.

BROCK DA, HASELKORN TS, GARCIA JR, BASHIRU, DOUGLAS TE, GALLOWAY J, BRODIE F, QUELLER DC, STRASSMANN JE (2018). Diversity of Free-Living Environmental Bacteria and Their Interactions With a Bactivorous Amoeba. Front Cell Infect Microbiol 8.

BUTTERY NJ, JACK CN, ADU-OPPONG B, SNYDER KT, THOMPSON CRL, QUELLER DC, STRASSMANN JE (2012). Structured growth and genetic drift raise relatedness in the social amoeba Dictyostelium discoideum. Biol Lett 8: 794-797.

BUTTERY NJ, ROZEN DE, WOLF JB, THOMPSON CRL (2009). Quantification of Social Behavior in D. discoideum Reveals Complex Fixed and Facultative Strategies. Curr Biol 19: 1373-1377.

CASTILLO DI, QUELLER DC, STRASSMANN JE (2011). Cell condition, competition, and chimerism in the social amoeba Dictyostelium discoideum. Ethol Ecol Evol 23: 262-273.

DAWKINS R (1976). The selfish gene. Oxford University Press, Oxford.

DAWKINS R, KREBS JR (1979). Arms races between and within species. Proc $R$ Soc Lond B Biol Sci 205: 489-511.

DISALVO S, BROCK DA, SMITH jeff, QUELLER DC, STRASSMANN JE (2014). In the social amoeba Dictyostelium discoideum, density, not farming status, determines predatory success on unpalatable Escherichia coli. BMC Microbiol 14. DISALVO S, HASELKORN TS, BASHIR U, JIMENEZ D, BROCK DA, QUELLER DC, STRASSMANN JE (2015). Burkholderia bacteria infectiously induce the proto-farming symbiosis of Dictyostelium amoebae and food bacteria. Proc Natl Acad ScI USA 112: E5029-E5037.

DOUGLAS TE, QUELLER DC, STRASSMANN JE (2017). Social amoebae mating types do not invest unequally in sexual offspring. J Evol Biol 30: 926-937.

DUBRAVCIC D, VAN BAALEN M, NIZAK C (2014). An evolutionarily significant unicellular strategy in response to starvation in Dictyostelium social amoebae.
F1000Res 3: 133-133

ENNIS HL, DAO DN, PUKATZKI SU, KESSIN RH (2000). Dictyostelium amoebae lacking an F-box protein form spores rather than stalk in chimeras with wild type. Proc Natl Acad Sci USA 97: 3292-3297.

ENNIS HL, SUSSMAN M (1975). Mutants of Dictyostelium discoideum Defective in Spore Germination. J Bact 124: 62-64.

FLETCHER D, MICHENER C (1987). Kin recognition in animals. John Wiley, Chichester, England.

FLOWERS JM, LI SI, STATHOS A, SAXER G, OSTROWSKI EA, QUELLER DC, STRASSMANN JE, PURUGGANAN MD (2010). Variation, sex, and social cooperation: Molecular population genetics of the social amoeba Dictyostelium discoideum. PLoS Genet 6: 1-14.

FORTUNATO A, QUELLER DC, STRASSMANN JE (2003). A linear dominance hierarchy among clones in chimeras of the social amoeba Dictyostelium discoideum: Hierarchies of clones in social amoebae. J Evol Biol 16: 438-445.

FOSTER KR, FORTUNATO A, STRASSMANN JE, QUELLER DC (2002). The costs and benefits of being a chimera. Proc $R$ Soc B Biol Sci 269: 2357-2362.

FOSTER KR, SHAULSKY G, STRASSMANN JE, QUELLER DC, THOMPSON CRL (2004). Pleiotropy as a mechanism to stabilize cooperation. Nature 431:693-696.

GARDNER A, WEST SA (2006). Demography, altruism, and the benefits of budding. $J$ Evol Biol 19: 1707-1716.

GILBERT OM, FOSTER KR, MEHDIABADI NJ, STRASSMANN JE, QUELLER DC (2007). High relatedness maintains multicellular cooperation in a social amoeba by controlling cheater mutants. Proc Natl Acad Scl USA 104: 8913-8917.

GILBERT OM, STRASSMANN JE, QUELLER DC (2012). High relatedness in a social amoeba: The role of kin-discriminatory segregation. Proc $R$ Soc $B$ Biol Sci 279: 2619-2624.

GOMER RH, FIRTEL RA (1987). Cell-autonomous determination of cell-type choice in Dictyostelium development by cell-cycle phase. Science 237: 758-762.

GRALKA M, STIEWE F, FARRELL F, MÖBIUS W, WACLAW B, HALLATSCHEK O (2016). Allele surfing promotes microbial adaptation from standing variation Ed. B Blasius. Ecol Lett 19: 889-898.

GRUENHEIT N, PARKINSON K, STEWART B, HOWIE JA, WOLF JB, THOMPSON CRL (2017). A polychromatic 'greenbeard' locus determines patterns of cooperation in a social amoeba. Nat Comm 8: 14171.

GRUENHEIT N, PARKINSON K, BRIMSON CA, KUWANA S, JOHNSON EJ, NAGAYAMA K, LLEWELLYN J, SALVIDGE WM, STEWART B, KELLER T, VAN ZON W, COTTER SL, THOMPSON CRL (2018). Cell Cycle Heterogeneity Can Generate Robust Cell Type Proportioning. Dev Cell 47: 494-508.e4.

HALL DW, FOX S, KUZDZAL-FICK JJ, STRASSMANN JE, QUELLER DC (2013). The Rate and Effects of Spontaneous Mutation on Fitness Traits in the Social Amoeba, Dictyostelium discoideum. G3 3: 1115-1127.

HALLATSCHEK O, HERSEN P, RAMANATHAN S, NELSON DR (2007). Genetic drift at expanding frontiers promotes gene segregation. Proc Natl Acad Sci USA 104: 19926-19930.

HALLATSCHEK O, NELSON DR (2010). Life at the front of an expanding population. Evolution 64: 193-206.

HAMILTON WD (1964a). The genetical evolution of social behavior. I. J Theo Biol 7: 1-16.

HAMILTON WD (1964b). The genetical evolution of social behaviour. II. J Theo Biol 7: $17-52$.

HIROSE S, BENABENTOS R, HO H, KUSPA A, SHAULSKY G (2011). Self-Recognition in Social Amoebae Is Mediated by Allelic Pairs of Tiger Genes. Science 333: 467-470.

HIROSE S, CHEN G, KUSPA A, SHAULSKY G (2017). The polymorphic proteins TgrB1 and TgrC1 function as a ligand-receptor pair in Dictyostelium allorecognition. J Cell Sci 130: 4002-4012.

HIROSES, SANTHANAMB, KATOH-KUROSAWAM, SHAULSKY G, KUSPAA(2015). Allorecognition, via TgrB1 and TgrC1, mediates the transition from unicellularity to multicellularity in the social amoeba Dictyostelium discoideum. Development 142: $3561-3570$

HO H-I, HIROSE S, KUSPA A, SHAULSKY G (2013). Kin Recognition Protects Cooperators against Cheaters. Curr Biol 23: 1590-1595.

HO H-I, SHAULSKY G (2015). Temporal regulation of kin recognition maintains recognition-cue diversity and suppresses cheating. Nat Comm 6: 7144. 
HOLLISB (2012). Rapid antagonistic coevolution between strains of the social amoeba Dictyostelium discoideum. Proc R Soc B Biol Sci 279: 3565-3571.

HUSS MJ (1989). Dispersal of Cellular Slime Molds by Two Soil Invertebrates. Mycologia 81: 677-682.

INGLIS RF, RYU E, ASIKHIA O, STRASSMANN JE, QUELLER DC (2017). Does high relatedness promote cheater-free multicellularity in synthetic lifecycles? J Evol Biol 30: 985-993.

KAUSHIKS, KATOCHB, NANJUNDIAHV (2006). Social behaviour in genetically heterogeneous groups of Dictyostelium giganteum. Behav EcolSociobio/59:521-530.

KAUSHIK S, NANJUNDIAH V (2003). Evolutionary Questions Raised by Cellular Slime Mould Development. Proc Indian Natl Sci Acad B69: 825-852.

KESSIN RH, GUNDERSEN GG, ZAYDFUDIM V, GRIMSON M (1996). How cellular slime molds evade nematodes. Proc Natl Acad Sci USA 93: 4857-4861.

KESSIN RH (2001). Dictyostelium: evolution, cell biology, and the development of multicellularity. Cambridge University Press, Cambridge, UK.

KHAREA, SANTORELLI LA, STRASSMANNJE, QUELLERDC, KUSPAA, SHAULSKY G (2009). Cheater-resistance is not futile. Nature 461: 980-982.

KHARE A, SHAULSKY G (2010). Cheating by Exploitation of Developmental Prestalk Patterning in Dictyostelium discoideum Ed. W Shou. PLoS Genet 6: e1000854.

KUZDZAL-FICKJJ, FOSTERKR, QUELLERDC, STRASSMANNJE (2007). Exploiting new terrain: an advantage to sociality in the slime mold Dictyostelium discoideum. Behav Ecol 18: 433-437.

KUZDZAL-FICK JJ, FOX SA, STRASSMANN JE, QUELLER DC (2011). High Relatedness Is Necessary and Sufficient to Maintain Multicellularity in Dictyostelium. Science 334: 1548-1551.

KUZDZAL-FICK JJ, QUELLER DC, STRASSMANN JE (2010). An invitation to die: Initiators of sociality in a social amoeba become selfish spores. Biol Lett6:800-802.

LEACH C, ASHWORTH J, GARROD D (1973). Cell sorting out during the differentiation of mixtures of metabolically distinct populations of Dictyostelium discoideum. Development 29: 647-661.

LEVIN SR, BROCK DA, QUELLER DC, STRASSMANN JE (2015). Concurrent coevolution of intra-organismal cheaters and resisters. J Evol Biol 28: 756-765.

LI Sil, PURUGGANAN MD (2011). The cooperative amoeba: Dictyostelium as a model for social evolution. Trends Genet 27: 48-54.

MADGWICK Philip G., STEWART B, BELCHER LJ, THOMPSON CRL, WOLF JB (2018). Strategic investment explains patterns of cooperation and cheating in a microbe. Proc Natl Acad Sci USA 115: E4823-E4832.

MEHDIABADI NJ, JACK CN, FARNHAM TT, PLATT TG, KALLA SE, SHAULSKY G, QUELLER DC, STRASSMANN JE (2006). Kin preference in a social microbe. Nature 442: 881-882.

MEHDIABADI NJ, KRONFORST MR, QUELLER DC, STRASSMANN JE (2009). Phylogeny, reproductive isolation and kin recognition in the social amoeba Dictyostelium purpureum. Evolution 63: 542-548.

NOH S, GEIST KS, TIAN X, STRASSMANN JE, QUELLER DC (2018). Genetic signatures of microbial altruism and cheating in social amoebas in the wild. Proc Natl Acad Sci USA 115: 3096-3101.

OSTROWSKI EA (2019). Enforcing Cooperation in the Social Amoebae. Curr Bio 29: R474-R484.

OSTROWSKI EA, KATOH M, SHAULSKY G, QUELLER DC, STRASSMANN JE (2008). Kin discrimination increases with genetic distance in a social amoeba. PLoS Biol 6: 2376-2382.

OSTROWSKIEA, SHENY, TIANX, SUCGANG R, JIANG H, QUJ, KATOH-KURASAWA M, BROCK DA, DINH C, LARA-GARDUNO F, et al., (2015). Genomic Signatures of Cooperation and Conflict in the Social Amoeba. Curr Biol 25: 1661-1665.

QUELLER D, PONTE E, BOZZARO S, STRASSMANN J (2003). Single-Gene Greenbeard Effects in the Social Amoeba Dictyostelium discoideum. Science 299: 105-106.

QUELLER DC (2016). Kin Selection and Its Discontents. Phil Sci 83: 861-872.

QUELLER DC, STRASSMANN JE (2018). Evolutionary Conflict. Annu Rev Ecol Evol Syst 49: 73-93.

QUELLER DC, STRASSMANN JE (2012). Experimental evolution of multicellularity using microbial pseudo-organisms. Biol Lett 9: 20120636-20120636.

RAPER KB (1984). The Dictyostelids. Princeton University Press, Princeton, NJ.

RATNIEKS FLW, FOSTER KR, WENSELEERS T (2006). Conflict resolution in insect societies. Annu Rev Ento 51: 581-608.

RUBIN M, MILLER AD, KATOH-KURASAWA M, DINH C, KUSPA A, SHAULSKY G (2019). Cooperative predation in the social amoebae Dictyostelium discoideum Ed. T Soldati. PLOS ONE 14: e0209438.

SANTORELLI LA, KUSPA A, SHAULSKY G, QUELLER DC, STRASSMANN JE (2013). A new social gene in Dictyostelium discoideum, chtB. BMC Evol. Biol. 13.

SANTORELLI LA, THOMPSON CRL, VILLEGAS E, SVETZ J, DINH C, PARIKH A, SUCGANG R, KUSPA A, STRASSMANN JE, QUELLER DC, SHAULSKY G (2008). Facultative cheater mutants reveal the genetic complexity of cooperation in social amoebae. Nature 451: 1107-1110.

SATHE S, KAUSHIK S, LALREMRUATAA, AGGARWAL RK, CAVENDER JC, NANJUNDIAH V (2010). Genetic Heterogeneity in Wild Isolates of Cellular Slime Mold Social Groups. Micro Ecol 60: 137-148.

SATHE S, KHETAN N, NANJUNDIAH V (2014). Interspecies and intraspecies interactions in social amoebae. J Evol Biol 27: 349-362.

SHAULSKY G, KESSIN RH (2007). The Cold War of the Social Amoebae. Curr Biol 17: R684-R692

SMITH jeff, QUELLER DC, STRASSMANN JE (2014). Fruiting bodies of the social amoeba Dictyostelium discoideum increase spore transport by Drosophila. BMC Evol Biol 14: 105.

SMITH jeff, STRASSMANNJE, QUELLERDC (2016). Fine-scale spatial ecology drives kin selection relatedness among cooperating amoebae. Evolution 70: 848-859.

STEPHENSON SL, LANDOLT JC (1992). Vertebrates as vectors of cellular slime moulds in temperate forests. Mycol Res 96: 670-672.

STRASSMANN JE (2016). Kin Discrimination in Dictyostelium Social Amoebae. J Eukaryot Microbiol 63: 378-383.

STRASSMANN JE, PAGE JR. RE, ROBINSON GE, SEELEYTD (2011). Kin selection and eusociality. Nature 471: E5-E5.

STRASSMANN JE, QUELLER DC (2011). Evolution of cooperation and control of cheating in a social microbe. Proc Natl Acad Sci USA 108. 10855-10862; DOI: 10.1073/pnas. 1102451108

STRASSMANN JE, ZHU Y, QUELLER DC (2000). Altruism and social cheating in the social amoeba Dictyostelium discoideum. Nature 408: 965-967.

SUTHERS HB (1985). Ground-feeding migratory songbirds as cellular slime mold distribution vectors. Oecologia 65: 526-530.

SWANSON AR, VADELL EM, CAVENDER JC (1999). Global distribution of forest soil dictyostelids. J Biogeo 26: 133-148

TARNITA CE (2017). The ecology and evolution of social behavior in microbes. $J$ Exp Biol 220: 18-24.

TARNITA CE, WASHBURNE A, MARTINEZ-GARCIA R, SGRO AE, LEVIN SA (2015). Fitness tradeoffs between spores and nonaggregating cells can explain the coexistence of diverse genotypes in cellular slime molds. Proc. Natl. Acad. Sci. USA 112: 2776-2781.

THOMPSON CR, KAY RR (2000). Cell-fate choice in Dictyostelium: intrinsic biases modulate sensitivity to DIF signaling. Dev Biol 227: 56-64.

TSUTSUI ND (2004). Scents of self: The expression component of self/non- self recognition systems. Ann Zool Fenn 41: 713-727.

VAN DYKEN JD, WADE MJ (2010). The Genetic Signature of Conditional Expression. Genetics 184: 557-570.

VAN VALEN L (1973). A new evolutionary law. Evol Theory 1: 1-30.

VOTAW HR, OSTROWSKI EA (2017). Stalk size and altruism investment within and among populations of the social amoeba. J Evol Biol 30: 2017-2030.

WEST SA, GRIFFIN AS, GARDNER A (2007). Evolutionary Explanations for Cooperation. Curr Biol 17: R661-R672.

WOLF JB, HOWIE JA, PARKINSON K, GRUENHEIT N, MELO D, ROZEN D, THOMPSON CRL (2015). Fitness Trade-offs Result in the Illusion of Social Success. Curr Biol 25: 1086-1090. 


\section{Further Related Reading, published previously in the Int. J. Dev. Biol.}

Deletion of etoposide-induced $2.4 \mathrm{~kb}$ transcript (ei24) reduced cell proliferation and aggregate-size in Dictyostelium discoideum Neha Gupta and Shweta Saran

Int. J. Dev. Biol. (2018) 62: 273-283

https://doi.org/10.1387/ijdb.170327ss

Bimodal distribution of motility and cell fate in Dictyostelium discoideum

Pavana Goury-Sistla, Vidyanand Nanjundiah and Gopal Pande

Int. J. Dev. Biol. (2012) 56: 263-272

https://doi.org/10.1387/ijdb.113384ps

Cell cycle phase, cellular $\mathrm{Ca} 2+$ and development in Dictyostelium discoideum.

MAzhar, PKKennady, G Pande, M Espiritu, W Holloman, D Brazill, RH Gomer and V Nanjundiah Int. J. Dev. Biol. (2001) 45: 405-414

http://www.intjdevbiol.com/web/paper/11330860

A cell type-specific effect of calcium on pattern formation and differentiation in dictyostelium discoideum.

R Basker, P Chhabra, P Mascarenhas and V Nanjundiah

Int. J. Dev. Biol. (2000) 44: 491-498

http://www.intjdevbiol.com/web/paper/11032184

Regulation of cell differentiation and pattern formation in Dictyostelium development. I Takeuchi, M Tasaka, K Okamoto and Y Maeda Int. J. Dev. Biol. (1994) 38: 311-319

http://www.intjdevbiol.com/web/paper/7981039

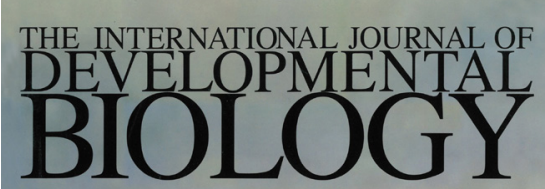

Volume 47 Nos. $7 / 8$

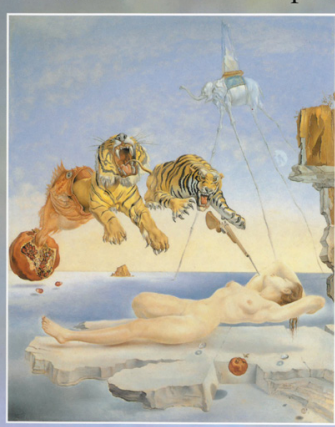

Evolution \& Development

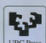

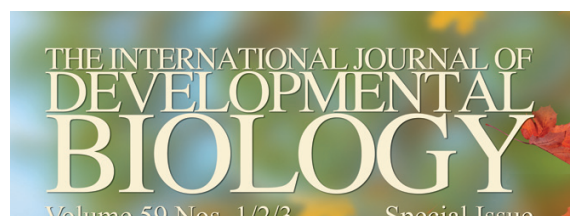

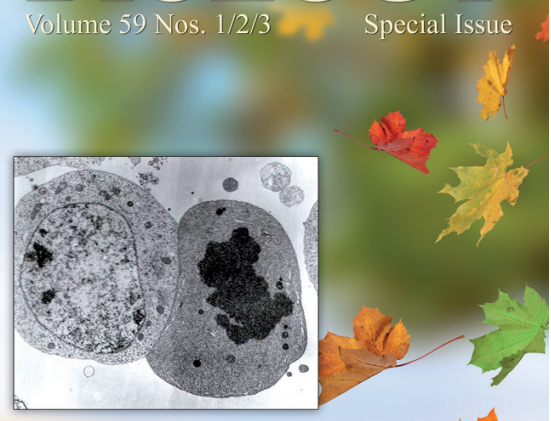

Cell Death in Development \& Tumors
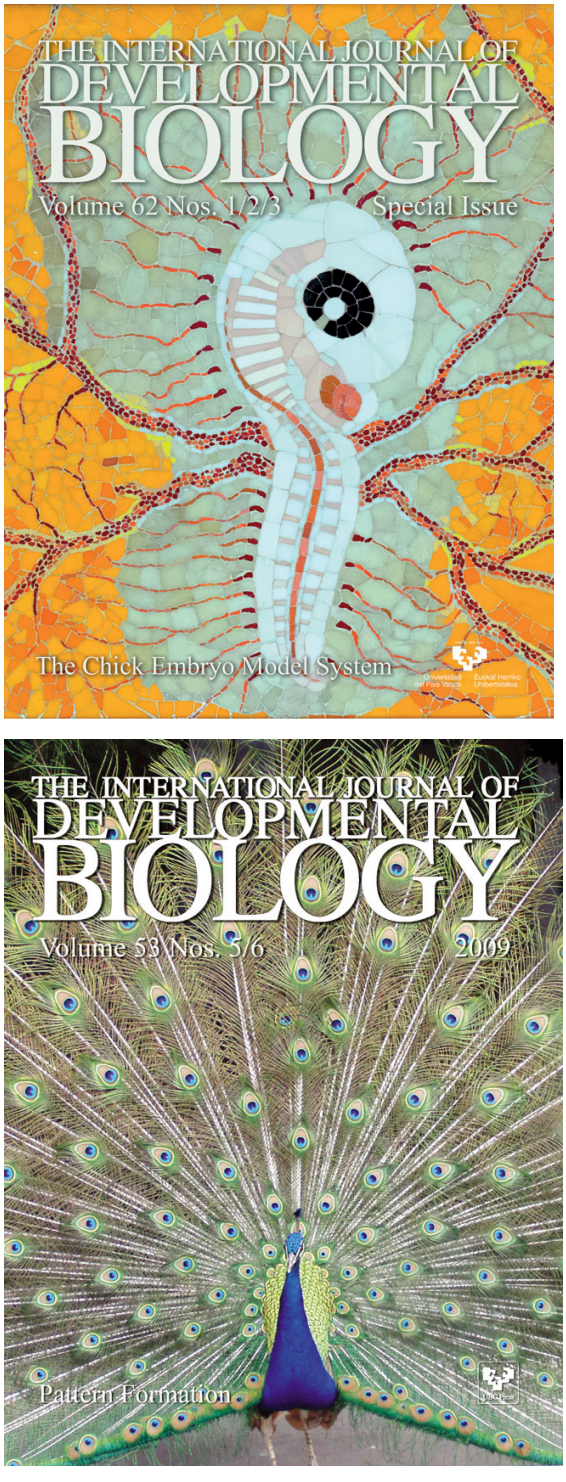